\title{
Study on Beneficiation of a Refractory Low Grade Oxidized Zinc Ore
}

\author{
Pengfei Zhang ${ }^{1,2, a}$, Haiyun Xie ${ }^{1,2, b}$, Chao Ding ${ }^{1, c}$, Likun Gao ${ }^{1,2, d}$, Xiong Tong ${ }^{1,2, e}$
}

(1.Faculty of Land Resource Engineering, Kunming University of Science and Technology Kunming 650093, China

2. State Key Laboratory of Complex Nonferrous Metal Resource Clean Utilization, Kunming 650093, China)

aEmail:1540028565@qq.com,bemail:xie-haiyun@163.com,cEmail:1053981006@qq.com, dEmail:likun_gao@126.com, ${ }^{\mathrm{e} E m a i l: x i o n g t o n g 2000 @ y a h o o . c o m ~}$

Key words: low-grade oxidized zinc ore; flotation; sulfurization-amination

Abstract: A low grade oxidized zinc mine of Lan ping contains $6.52 \% \mathrm{Zn}$ with a high ratio of oxidized zinc ores and a little sulfide minerals.In order to utilize this kind of ore,the test treats oxidized zinc ore as a kind of valuable mineral and an experimental study on beneficiation is carried out in which the process flow-sheets of sulfurization-amination is used .A good technical index with $45.28 \%$ of zinc concentrate at a $\mathrm{Zn}$ recovery of $71.45 \%$ is achieved.

\section{Introduction}

Lanping zinc oxide ore in Yunnan province is the largest zinc oxide deposits proved reserves in China at present, With characteristics of a high ratio of oxidized and fine disseminated extent, it has great difficulty for mineral processing ${ }^{[1]}$. A large number of low grade zinc oxide ore has been unable to use.Flotation method plays an important role in the treatment of zinc oxide ore in industrial production ${ }^{[2]}$.To improve the grade and recovery of zinc are still problems in the separation of zinc oxide ore .According to the analysis of related literature at home and abroad, this paper makes an experimental study on beneficiation of a low grade oxidized zinc ore in Lanping with sulfurization-amination, being of great practical significance for improving the utilization rate of zinc resources.

\section{Material and method}

\section{Material}

The material used in the study is taken from Lanping in Yunnan.Multi-element analysis results of crude ore are shown in table 1, Analysis results of zinc phase are shown in table 3.

Table 1 Multi-element analysis results of crude ore/\%

\begin{tabular}{ccccccccc}
\hline Element & $\mathrm{Zn}$ & $\mathrm{Pb}$ & $\mathrm{S}$ & $\mathrm{Fe}$ & $\mathrm{SiO}_{2}$ & $\mathrm{CaO}$ & $\mathrm{MgO}$ & $\mathrm{Al}_{2} \mathrm{O}_{3}$ \\
\hline Content & 6.52 & 0.63 & 1.54 & 5.56 & 25.78 & 22.43 & 1.65 & 2.43 \\
\hline \multicolumn{7}{c}{ Table 2 } & Analysis results of zinc phase/\% \\
\hline Zinc phase & Carbonate & Silicate & Sulfide & ferrite and other zinc & Total zinc \\
\hline Zn content & 3.45 & 2.72 & 0.27 & 0.083 & 6.52 \\
Distribution & 52.91 & 41.71 & 4.11 & 1.27 & 100.00 \\
\hline
\end{tabular}

As can be seen from the table 1 and 2: The characteristics of zinc ore include low grade, high oxidation 
rate. the grade of zinc is $6.52 \%$, oxidation rate is $92.17 \%$. The content of gangue mineral is high, and the total content of $\mathrm{CaO}$ and $\mathrm{MgO}$ is $24.08 \%$ in alkaline gangue, the content of $\mathrm{SiO}_{2}$ is $25.78 \%$.Apparently, the ore is a refractory low grade oxidized zinc ore.

\section{Method}

In zinc oxide mineral sorting, the method of sulfurization-amination has a significant effect ${ }^{[3]}$, and the method is used in this study for treating oxidized zinc ore in Lanping. In this paper, the flotation reagents include $\mathrm{pH}$ regulator, dispersant which is sodium carbonate, inhibitor that are sodium hexametaphosphate and sodium silicate, vulcanizing agent which is sodium sulfide, and flotation collector that is octadecylamine. The equipment include XMQ - $240 * 90$,cone ball mill,the XFD single groove flotation machine ( $0.75 \mathrm{~L}$ and $1 \mathrm{~L}$ ), sieve set and DL - $5 \mathrm{C}$ disk vacuum filter.

\section{Test results and discussions}

\section{Grinding fineness and the dosage of reagents tests in the roughing}

In the flotation of low grade zinc oxide ore, the grinding fineness is an important influencing factors, the proper dosage of reagents is crucial to the promotion of flotation index.In this part,conditions tests about grinding fineness and the dosage of flotation reagents are conducted, flow-sheets of condition test are shown in Fig.1.

\section{Grinding fineness test}

To determine the best grinding fineness of dressing experiment, grinding fineness test is done.The concentration of grinding was $65 \%$, The dosage of various reagents as follows: $\mathrm{Na}_{2} \mathrm{C}$ $\mathrm{O}_{3}(1300 \mathrm{~g} / \mathrm{t}), \mathrm{Na}_{2} \mathrm{SiO}_{3}(400 \mathrm{~g} / \mathrm{t}), \mathrm{Na}_{6} \mathrm{O}_{18} \mathrm{P}(250 \mathrm{~g} / \mathrm{t}), \mathrm{Na}_{2} \mathrm{~S}(7000 \mathrm{~g} / \mathrm{t}), 0$ ctadecylamine(400g/t),2 ${ }^{\#} 0 \mathrm{il}(10 \mathrm{~g} / \mathrm{t}) . \mathrm{f}$ low-sheets of test are shown in Fig.1,Results of grinding fineness test are shown in table 3.

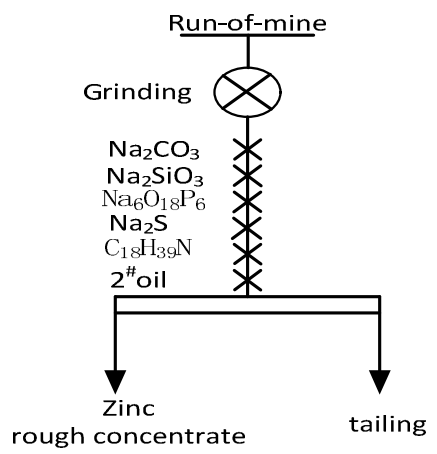

Table3 Results of grinding fineness test $/ \%$

Fig.1 flow-sheets of condition test

According to the results in table 3 can be concluded that: with the increase of the content of -0.074 $\mathrm{mm}$,the grade and recovery of zinc firstly increase then decrease, when the content of $-0.074 \mathrm{~mm}$ is $89.78 \%$, the grade of zinc is $17.97 \%$, the recovery rate of zinc was $42.94 \%$.By contrast, the grade and the recovery of zinc is the best index , so the best grinding fineness is that "- $0.074 \mathrm{~mm}$ occupies $89.78 \% "$ ".

\section{The dosage of $\mathrm{Na}_{2} \mathrm{CO}_{3}$ test}

Changeless conditions are $450 \mathrm{~g} / \mathrm{t}\left(\mathrm{Na}_{2} \mathrm{SiO}_{3}\right), 250 \mathrm{~g} / \mathrm{t}\left(\mathrm{Na}_{6} \mathrm{O}_{18} \mathrm{P}_{6}\right), 7000 \mathrm{~g} / \mathrm{t}\left(\mathrm{Na}_{2} \mathrm{~S}\right), 400 \mathrm{~g} / \mathrm{t}$ $\left(\mathrm{C}_{18} \mathrm{H}_{39} \mathrm{~N}\right)$ and $10 \mathrm{~g} / \mathrm{t}$ ( $2^{\#}$ oil).flow-sheets of test are shown in Fig.1,The influence of dosage of sodium carbonate on the flotation indexes of zinc concentrate are shown in Table 4 .According to the results in Table 4 can be concluded that: with the increase of the dosage of $\mathrm{Na}_{2} \mathrm{CO}_{3}$, the grade and recovery of zinc firstly increase then decrease, When the best dosage of $\mathrm{Na}_{2} \mathrm{CO}_{3}$ is $1500 \mathrm{~g} / \mathrm{t}$, the grade of zinc is $9.46 \%$, the recovery rate of zinc reached $88.24 \%$.

\section{The dosage of $\mathrm{Na}_{2} \mathrm{SiO}_{3}$ and $\mathrm{Na}_{6} \mathrm{O}_{18} \mathrm{P}_{6}$ test}

The dosage of $\mathrm{Na}_{2} \mathrm{SiO}_{3}$ and $\mathrm{Na}_{6} \mathrm{O}_{18} \mathrm{P}_{6}$ as follows: $\mathrm{A}(300 \mathrm{~g} / \mathrm{t}+100 \mathrm{~g} / \mathrm{t}), \mathrm{B}(400 \mathrm{~g} / \mathrm{t}+150 \mathrm{~g} / \mathrm{t}), \mathrm{C}(500 \mathrm{~g} / \mathrm{t}+20$ $0 \mathrm{~g} / \mathrm{t}), \mathrm{D}(600 \mathrm{~g} / \mathrm{t}+250 \mathrm{~g} / \mathrm{t}), \mathrm{E}(700 \mathrm{~g} / \mathrm{t}+300 \mathrm{~g} / \mathrm{t})$. Other conditions are $1500 \mathrm{~g} / \mathrm{t}\left(\mathrm{Na}_{2} \mathrm{CO}_{3}\right), 7000 \mathrm{~g} / \mathrm{t}\left(\mathrm{Na}_{2} \mathrm{~S}\right), 400 \mathrm{~g} / \mathrm{t}$ 
$\left(\mathrm{C}_{18} \mathrm{H}_{39} \mathrm{~N}\right), 10 \mathrm{~g} / \mathrm{t}\left(2{ }^{\#}\right.$ oil $)$. Flow-sheets of test are shown in Fig.1, The results are shown in Table 5 and it shows that the grade and recovery rate of zinc firstly increase then decrease with the increase of $\mathrm{Na}_{2} \mathrm{SiO}_{3}$ and $\mathrm{Na}_{6} \mathrm{O}_{18} \mathrm{P}_{6}$. It can be seen that the best dosage of $\mathrm{Na}_{2} \mathrm{SiO}_{3}$ and $\mathrm{Na}_{6} \mathrm{O}_{18} \mathrm{P}$ is $\mathrm{C}(500 \mathrm{~g}$ $/ \mathrm{t}+200 \mathrm{~g} / \mathrm{t})$.

\section{The dosage of $\mathrm{Na}_{2} \mathrm{~S}$ test}

Sodium sulfide has activation properties for zinc oxide ore in sulfurization-aminatio, The different dosage affects the flotation index.Changeless conditions are $1500 \mathrm{~g} / \mathrm{t}\left(\mathrm{Na}_{2} \mathrm{CO}_{3}\right), 500 \mathrm{~g} / \mathrm{t}\left(\mathrm{Na}_{2} \mathrm{SiO}_{3}\right), 200 \mathrm{~g} / \mathrm{t}\left(\mathrm{Na}_{6} \mathrm{O}_{18} \mathrm{P}_{6}\right)$, $400 \mathrm{~g} / \mathrm{t}\left(\mathrm{C}_{18} \mathrm{H}_{39} \mathrm{~N}\right), 10 \mathrm{~g} / \mathrm{t}\left(2^{\#}\right.$ oil),flow-sheets of test are shown in Fig.1, Results in the dosage of $\mathrm{Na}_{2} \mathrm{~S}$ test are

\begin{tabular}{ccc}
\hline $\mathrm{Na}_{2} \mathrm{CO}_{3}(\mathrm{~g} / \mathrm{t})$ & $\beta / \%$ & $\varepsilon / \%$ \\
\hline 500 & 17.03 & 85.21 \\
1000 & 17.81 & 86.27 \\
1500 & 19.46 & 88.24 \\
2000 & 18.32 & 84.65 \\
2500 & 17.96 & 83.92 \\
\hline
\end{tabular}

Table 4 Results in the dosage of $\mathrm{Na}_{2} \mathrm{CO}_{3}$

\begin{tabular}{crr}
\hline $\mathrm{Na}_{2} \mathrm{SiO}_{3} / \mathrm{Na}_{6} \mathrm{O}_{18} \mathrm{P}_{6}(\mathrm{~g} / \mathrm{t})$ & $\beta / \%$ & $\varepsilon / \%$ \\
\hline $\mathrm{A}$ & 14.83 & 80.25 \\
$\mathrm{~B}$ & 15.76 & 82.14 \\
$\mathrm{C}$ & 18.26 & 83.44 \\
$\mathrm{D}$ & 17.81 & 79.52 \\
$\mathrm{E}$ & 16.51 & 75.62 \\
\hline
\end{tabular}

Table5 Results in the dosage of $\mathrm{Na}_{2} \mathrm{SiO}_{3}$ and $\mathrm{Na}_{6} \mathrm{O}_{18} \mathrm{P}_{6}$ test

shown in Table 6 and it shows that the grade and recovery rate of zinc firstly increase then decrease with the increase of $\mathrm{Na}_{2} \mathrm{~S}$, When $\mathrm{Na}_{2} \mathrm{~S}$ is $8000 \mathrm{~g} / \mathrm{t}$, the grade of zinc was $18.26 \%$, the recovery rate of zinc is $81.03 \%$, By contrast, $8000 \mathrm{~g} / \mathrm{t}$ is the best dosage of sodium sulfide.

\begin{tabular}{ccc}
\hline $\mathrm{Na}_{2} \mathrm{~S} /(\mathrm{g} / \mathrm{t})$ & $\beta / \%$ & $\varepsilon / \%$ \\
\hline 4000 & 15.36 & 65.52 \\
6000 & 17.43 & 78.61 \\
8000 & 18.26 & 81.03 \\
10000 & 17.51 & 79.02 \\
12000 & 16.78 & 72.45 \\
\hline
\end{tabular}

Table 6 Results in the dosage of $\mathrm{Na}_{2} \mathrm{~S}$ test

\begin{tabular}{ccc}
\hline $\mathrm{C}_{18} \mathrm{H}_{39} \mathrm{~N} /(\mathrm{g} / \mathrm{t})$ & $\beta / \%$ & $\varepsilon / \%$ \\
\hline 300 & 17.28 & 62.35 \\
400 & 18.32 & 65.13 \\
500 & 18.97 & 82.84 \\
600 & 19.03 & 70.22 \\
700 & 18.25 & 64.53 \\
\hline
\end{tabular}

Table 7 Results in the dosage of $\mathrm{C}_{18} \mathrm{H}_{39} \mathrm{~N}$ test

\section{The dosage of octadecylamine test}

$\mathrm{C}_{18} \mathrm{H}_{39} \mathrm{~N}$ is used as zinc oxide mineral collector in the test.Changeless conditions are $1500 \mathrm{~g} / \mathrm{t}\left(\mathrm{Na}_{2} \mathrm{CO}_{3}\right), 500 \mathrm{~g} / \mathrm{t}\left(\mathrm{Na}_{2} \mathrm{SiO}_{3}\right), 200 \mathrm{~g} / \mathrm{t}\left(\mathrm{Na}_{6} \mathrm{O}_{18} \mathrm{P}_{6}\right), 8000 \mathrm{~g} / \mathrm{t}\left(\mathrm{Na}_{2} \mathrm{~S}\right), 10 \mathrm{~g} / \mathrm{t}$ (2 $2^{\#}$ oil) .flow-sheets of test are shown in Fig.1, Results in the dosage of $\mathrm{C}_{18} \mathrm{H}_{39} \mathrm{~N}$ test are shown in Table 7 and it shows that the grade and recovery of zinc firstly increase then decrease with the increase of the dosage of $\mathrm{C}_{18} \mathrm{H}_{39} \mathrm{~N}$, when the dosage of the $\mathrm{C}_{18} \mathrm{H}_{39} \mathrm{~N}$ is $500 \mathrm{~g} / \mathrm{t}$, the grade of zinc is $18.97 \%$, the recovery of zinc is $82.84 \%$, when the dosage of $\mathrm{C}_{18} \mathrm{H}_{39} \mathrm{~N}$ is $600 \mathrm{~g} / \mathrm{t}$, although the grade of zinc is $19.03 \%$, the recovery of zinc is only $70.22 \%$.the test can confirm that the best dosage of $\mathrm{C}_{18} \mathrm{H}_{39} \mathrm{~N}$ is $500 \mathrm{~g} / \mathrm{t}$.

\section{Open circuit test}

This study makes aopen circuit test which is first roughing separation,three times concentrations, double scavengings.flow-sheets of test are shown in Fig.2,Results of open circuit test are shown in Table 8 and it shows that the grade of zinc concentrate can reach $46.20 \%$, the recovery of zinc concentrate can reach $59.40 \%$.

\section{Closed circuit test}

This study makes a closed-circuit test which is the first roughing separation, three 
times concentrations, double scavengings.flow-sheets of closed-circuit test is showed in Fig.3 .Results of closed-circuit test are shown in Table 9 and it shows that the yield of zinc concentrate is $10.29 \%$, the grade of zinc is $45.28 \%$, the recovery of zinc reaches $71.45 \%$, it is confirmed that the technological conditions and the process scheme which are decided by the test can recover zinc mineral from low grade zinc oxide ore better.

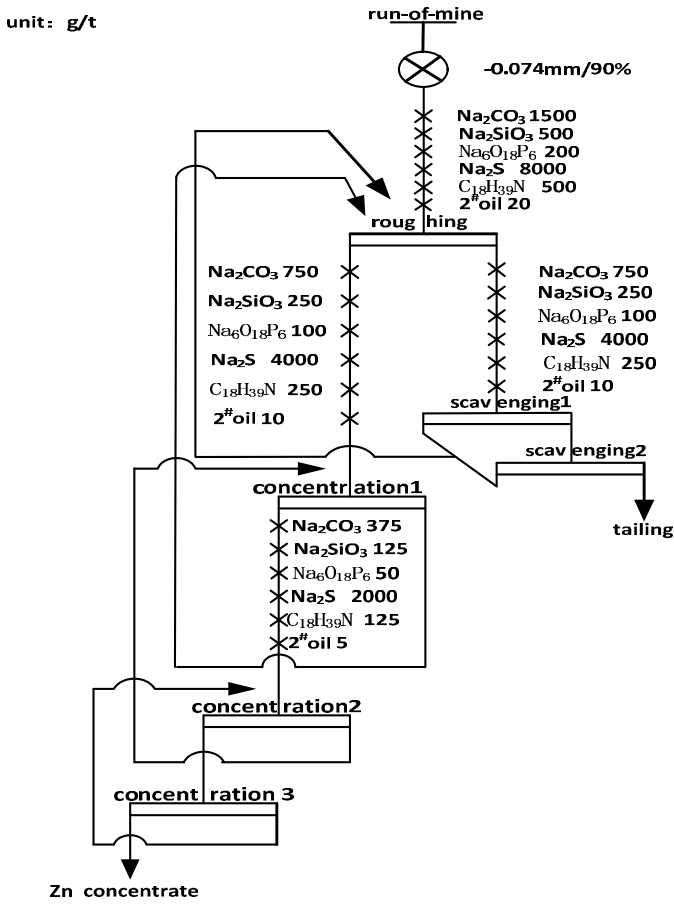

Fig.3 flow-sheets of closed-circuit test

Table 8 Results of open circuit test/\%

\begin{tabular}{cccc}
\hline Product name & $\gamma / \%$ & $\beta / \%$ & $\varepsilon / \%$ \\
\hline Zn concentrate & 6.75 & 46.20 & 48.50 \\
Middling 1 & 5.67 & 3.51 & 3.10 \\
Middling 2 & 0.84 & 14.06 & 1.84 \\
Middling 3 & 0.86 & 9.67 & 1.29 \\
Middling 4 & 11.76 & 22.29 & 40.77 \\
Middling 5 & 8.12 & 3.93 & 4.96 \\
Tailing & 66.00 & 1.53 & 15.84 \\
Summation & 100.0 & & 100.00 \\
Run-of-mine & 100.0 & 6.43 & 100.00 \\
\hline
\end{tabular}

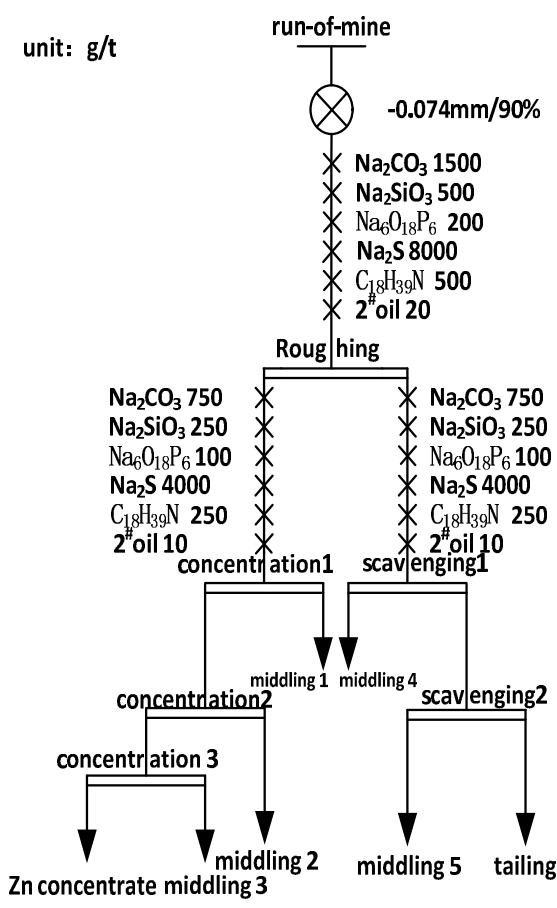

Fig. 2 flow-sheets of open circuit test

Table 9 Results of closed-circuit test/\%

\begin{tabular}{|c|c|c|c|}
\hline $\begin{array}{c}\text { Product } \\
\text { name }\end{array}$ & $\gamma / \%$ & $\beta / \%$ & $\varepsilon / \%$ \\
\hline $\begin{array}{c}\mathrm{Zn} \\
\text { concentrate }\end{array}$ & 10.29 & 45.28 & 71.45 \\
\hline Tailing & 89.71 & 2.07 & 28.55 \\
\hline Run-of-mine & 100 & 6.52 & 100 \\
\hline
\end{tabular}

\section{Conclusions}

Mainly containing zinc, Lanping low grade zinc oxide ore is a kind of ore difficult to complete separation with high oxidation rate and gangue mineral. The test processings run-of-mine with the method of sulfurization-amination so that gains the better index that the yield of zinc concentrate is $10.29 \%$, the grade of zinc is $45.28 \%$, the recovery of zinc is $71.45 \%$.

\section{Acknowledgements}

This work was financially supported by the Natural Science Foundation of China (Grant No.51464030). 


\section{References}

[1]XinpingZhang,XiuyingZhou,ShuqiuWang, etc. Study on new technology about the flotation of Lanping lead-zinc oxide ore [J].Mining and Metallurgy.1995(3):38-43.

[2] Yan Song, Quanjun Liu, Fuqiang Chang.Flotation present situation and research progress of zinc oxide ore [J]. Mining and Metallurgy .2012, 21(2) : 19-22.

[3]YushuangZhu,JianguangZhu.The chemical principle of flotation reagents[M].

Central South University press,2013. 